\title{
Identification and Characterization of the Lipid Transport System in the Tarantula Grammostola rosea
}

\author{
Aldana Laino, Monica Cunningham, Gustavo Suárez, Carlos Fernando Garcia* \\ Instituto de Investigaciones Bioquímicas de La Plata (INIBIOLP), CCT-La Plata CONICET-UNLP, \\ La Plata, Argentina \\ Email: ${ }^{*}$ cfgarcia1123@yahoo.com.ar
}

Received 30 October 2014; revised 3 December 2014; accepted 17 December 2014

Copyright $@ 2015$ by authors and Scientific Research Publishing Inc.

This work is licensed under the Creative Commons Attribution International License (CC BY). http://creativecommons.org/licenses/by/4.0/

(c) (i) Open Access

\section{Abstract}

Lipids due to its hydrophobic nature are transported in the hemolymph mainly by lipoproteic fractions. In the present work we studied the lipoproteic fractions present in the hemolymph of the spider Grammostola rosea. Through ultracentrifugation two lipoproteic fractions are isolated, one of high density named Gr-HDL $(\delta=1.13-1.15 \mathrm{~g} / \mathrm{ml})$ and the other of very high density called Gr-VHDL ( $\delta=1.24-1.27 \mathrm{~g} / \mathrm{ml}) \mathrm{Gr}-\mathrm{VHDL}$ in hemolymph is majority in relation to Gr-HDL. In this sense Gr-VHDL fraction has $\mathbf{9 8 . 6 \%}$ of hemolymphatic proteins, and $\mathbf{8 9 . 3 \%}$ of lipids presents in the hemolymph. Both lipoproteic fractions possess phospholipids such as majority lipids (phosphatidylcholine and phosphatidylethanolamine) and 18:1, 16:0, 18:2 and 18:0 as the major fatty acids. In order to confirm the role played by lipoproteic fractions in vitro assays with different ${ }^{14} \mathrm{C}$-lipid were performed. It was observed that Gr-VHDL takes up mainly free fatty acids and triacylglycerols unlike that observed for Gr-HDL in relation to phosphatidylcholine. Through electrophoresis it was observed that Gr-VHDL has three proteins: a predominant band of $68 \mathrm{kDa}$ and two others of 99 and $121 \mathrm{kDa}$. Gr-HDL displayed a predominant band of $93 \mathrm{kDa}$, and other minority of $249 \mathrm{kDa}$. In conclusion, this study reports lipid characterization of the lipoproteic fractions present in the hemolymph of the tarantula, $G$. rosea. The role of each lipoproteic fraction in relation to lipid uptake is sustained by in vitro assays. Similarities and differences are found when it is compared to lipoproteins of only the three species of spiders studied.

\section{Keywords}

Lipoproteins, Hemocyanin, Arachnids, Lipids

\footnotetext{
${ }^{*}$ Corresponding author.
} 


\section{Introduction}

Lipids are a heterogeneous group of molecules involved in many vital functions such as energy storage, formation of different structures, source of essential nutrients, vitamins, and chemical messengers. In general, hydrophobic characteristics of lipids determine their circulation mode in the aqueous fluids of animals as particles called lipoproteins.

Arthropod lipid circulation mechanisms are well known only in insects and crustaceans. Insect lipids are mostly carried by a lipoprotein transporting a great quantity of diacylglycerols [DAG] named lipophorin [1]-[5]. In crustaceans, lipids are transported by high-density lipoproteins (HDL) mostly in the form of phospholipids [PL] [6]-[10]. Surprisingly, scarce information is available for arachnids, where only in three out of 43,600 species of the described spiders, lipoproteic fractions have been isolated and characterized [11]-[16].

The first spider which hemolymphatic lipoproteins were characterized was the tarantula Eurypelma californicum (a nomen dubium that probably corresponds to Aphonopelma hentzi, following Nentwig, 2012) (Araneae, Theraphosidae). Haunerland and Bowers [15], on the basis of density gradient ultra centrifugation of hemolymph, detected three distinct protein fractions in this species. One subnatant corresponds to hemocyanin [Hc], and two others float at lower densities, which were identified as lipoproteins with HDL and VHDL characteristics. HDL with a hydrated density of $1.12 \mathrm{~g} / \mathrm{ml}$ is composed of approximately $44 \%$ lipid (mainly DAG and PL). In contrast, VHDL fraction with density of $1.28 \mathrm{~g} / \mathrm{ml}$ is composed of approximately $8 \%$ lipid [15].

Stratakis et al. [16] purified and characterized a VHDL from tarantula hemolymph with a density of $1.23 \mathrm{~g} / \mathrm{ml}$. Its lipid content from 16\% to 19\% (mainly PL and free fatty acids [FFA]) apparently differs from that observed by Haunerland and Bowers [15].

Lipid transport hemolymphatic system of Polybetes pythagoricus (Araneae, Sparassidae) is composed of three lipoproteic fractions: two HDLs fractions named HDL-1 $(\delta=1.13 \mathrm{~g} / \mathrm{ml}, 28 \%$ lipids by wt) and HDL-2 $(\delta=1.18$ $1.20 \mathrm{~g} / \mathrm{ml}, 3.6 \%$ lipids by wt), and a VHDL fraction ( $\delta=1.21-1.24 \mathrm{~g} / \mathrm{ml}, 3.5 \%$ lipids by wt). Their hemolymph concentrations are 2.3, 23.6 and $45.4 \mathrm{mg}$ of protein/ $\mathrm{ml}$ hemolymph, respectively. Circulating lipids in $P$. pythagoricus (3.41 mg/ml hemolymph) are therefore carried by VHDL (48.7\%), HDL-1 (26.2\%), and HDL-2 (25.1\%) [11] [14]. HDL-1 and VHDL fractions mainly transport phosphatidylcholine [PC], and in a lesser extent FFA, triacylglycerols [TAG] and phosphatidylethanolamine [PE]. The latter has a bluish coloration given by the high amount of Hc which was described as apolipoprotein [11] [14].

Two HDLs fractions were isolated from the hemolymphatic plasma of the spider Latrodectus mirabilis (Araneae, Theridiidae). HDL-1 fraction has a density of $1.13 \mathrm{~g} / \mathrm{ml}$ and HDL-2 fraction of $1.19-1.20 \mathrm{~g} / \mathrm{ml}$; their hemolymph concentrations are 4.83 and $31.6 \mathrm{mg}$ of protein/ml hemolymph, respectively. Circulating lipids carried by HDL- 1 are $80 \%$ and those by HDL-2 are $20 \%$. HDL- 1 mainly transports PC, FFA, and TAG. HDL-2 characterized by having Hc transports FFA, PC and cholesterol [CHOL] among others [12].

Hemocyanin [HC] plays its principal role as oxygen carrier, but it also has other properties and/or functions such as phenoloxidase activity, antimicrobial activity and apolipoprotein associated with the majority of circulating lipids [12]-[14] [17]-[22]. The hemocyanin-lipids interaction was reported for the first time by Zatta [23] who determined the existence of small amounts of PL bound to Hc of the crab Carcinus maenas; he assigned a stabilizing role in protein structure to this lipid fraction.

The amount of lipids was found to be significant in lipoproteins containing Hc as apolipoprotein in the spiders P. pythagoricus and L. mirabilis. In fact, though VHDL and HDL-2 fractions have a low lipid/protein ratio, they are of great quantitative importance in $P$. pythagoricus hemolymph, since they are bound to two thirds of hemolymphatic lipids [14] and the same occurrence, though in a minor proportion, was observed in the HDL-2 of $L$. mirabilis [12].

Recently, we have demonstrated for the first time that the midgut diverticula of arachnids are a main storage site and a major lipid metabolic center involved in the uptake and mobilization of lipids. It also clearly demonstrates that innovatively the VHDL (fraction with Hc) from P. pythagoricus participates in the lipid transport from and toward tissues [24] [25].

The aim of our work was to identify and characterize the components of the lipid transport system in the spider Grammostola rosea (Theraphosidae). We show data of the lipid composition of hemolymphatic fractions. Also with the use of radiolabelled lipids we comparatively evaluated the uptake of different lipids (FFA, PC and TAG) in the lipoproteic fractions and hemocytes present in hemolymph. 


\section{Materials and Methods}

\subsection{Sampling and Isolation of Lipoproteins}

Adults females of G. rosea (13 to 18 gr) were maintained in the laboratory at $22^{\circ} \mathrm{C}$ under a $14 / 10 \mathrm{~h} \mathrm{~L}$ :D photoperiod. The spiders were fed with cockroaches (Blaptica dubia) and water. The specimens were anesthetized using $\mathrm{CO}_{2}$ similar to Baumann et al. [26]. Hemolymph samples were collected using a syringe with a needle designed for animal injection (Hamilton Co.) with $0.1 \mathrm{~N}$ of sodium citrate as anticoagulant in accordance with Garcia et al. [27]; with the addition of a protease inhibitor cocktail 1/1000 v/v (Sigma Chemicals, St. Louis, MO, USA). The extraction was performed by needling one of the back legs. After hemolymph collection, the spiders were fed and watered.

Hemocytes were isolated by diluting hemolymph in buffer Tris-HCl $0.1 \mathrm{M}, \mathrm{pH}$ 8, centrifuged at $720 \mathrm{~g}$ for 10 min, them the pellet was resuspended and centrifuged again at $720 \mathrm{~g}$ for 30 min following the methodology by Laino et al. [25].

The isolation of lipoproteic fractions with and without Hc was performed using ultracentrifugation in density gradient, following the methodology previously employed for hemolymph of spiders [12] [14] [18]. Aliquots of clear blue hemolymph $(1.4 \mathrm{ml}$ ) were overlayed on $3 \mathrm{ml} \mathrm{NaBr}$ solution (density $1.35 \mathrm{~g} / \mathrm{ml}$ ) and centrifuged at $178,000 \mathrm{~g}$ at $10^{\circ} \mathrm{C}$ for $22 \mathrm{~h}$ in a Beckman L8 $70 \mathrm{M}$ centrifuge with a SW 60 Ti rotor. As the plasma density was $1.006 \mathrm{~g} / \mathrm{ml}$, a saline solution of the same density was run simultaneously as blank. The total volume of the tubes was fractioned from top to bottom into $0.2 \mathrm{ml}$ aliquots. The protein content of each fraction was monitored spectrophotometrically at $280 \mathrm{~nm}$.

\subsection{Protein Analysis}

Total protein concentration from different isolated lipoproteic fractions were measured colorimetrically by the method of Lowry et al. [28]. The apoproteins were analyzed by dissociating electrophoresis using a $4 \%-23 \%$ SDS-PAGE [29]. Gels were stained with Coomassie Brilliant Blue R-250 (Sigma Chemical Co.). Molecular weights were calculated as previously described [30].

\subsection{Lipid Analysis}

Lipids from lipoproteins were extracted following the procedure of Folch et al. [31]. Quantitative determination of lipid classes was performed by thin layer chromatography (TLC) coupled to a flame ionization detector (FID) in an Iatroscan apparatus model TH-10 (Iatron Laboratories, Tokyo, Japan), after separation on Chromarods type S-III [24] [32]. Lipid classes were quantified using monoacylglycerol as internal standard. The general procedure for separation, identification, and quantification of lipids was similar to that described in a previous work [14].

\subsection{Fatty Acid Analysis}

Fatty acid methyl esters (FAME) from total lipids from hemolymphatic lipoproteins were prepared with $\mathrm{BF}_{3^{-}}$ $\mathrm{MeOH}$, according to the method of Morrison and Smith [33]. The analysis was performed by gas-liquid chromatography (GLC-FID) using an HP-6890 capillary GLC (Hewlett Packard, Palo Alto, CA) fitted with an Omegawax 250 fused silica column, $30 \mathrm{~m} \times 0.25 \mathrm{~mm}$, with $0.25 \mu \mathrm{m}$ phase (Supelco, Bellefonte, CA). Peaks were identified by comparing the retention times with those from a mixture of standard methyl esters according to Garcia et al. [27].

\subsection{Lipid Uptake by Hemolymphatic Lipoproteins and Hemocytes}

In order to explore in the tarantula $G$. rosea the role played by hemolymphatic lipoprotein fractions and hemocytes in the uptake of different lipids, a series of experiments were performed following the methodology employed in arachnids by Laino et al. [25] with modifications. $0.5 \mathrm{ml}$ of hemolymph was incubated in vitro for 1 hour in $50 \mathrm{mM}$ potassium phosphate buffer $\mathrm{pH} 7.4$, with the following radiolabelled lipids in two different concentrations (low concentration of $0.16 \mu \mathrm{Ci}$ and high concentration of $0.16 \mu \mathrm{Ci}+500 \mu \mathrm{g}$ of non-radiolabelled lipid) of: free fatty acid $\left(\left(1-{ }^{14} \mathrm{C}\right)\right.$ palmitic acid), phosphoglyceride ((dipalmitoyl-1- $\left.-{ }^{14} \mathrm{C}\right)$ phosphatidylcholine), and triacylglyceride ((carboxyl- $\left.{ }^{14} \mathrm{C}\right)$ triolein). The choice of the lipids was based on the difference in polarity, there- 
fore different ways of vehiculization in an aqueous means were used. FFA was administered as ammonium salt according to Laino et al. [24], PC was administered as extruded liposomes similar to Garcia et al. [34] and TAG by means of sodium cholate (Sigma Chemical Co.) following the methodology used by Cunningham et al. [18]. FFA was provided by Amersham, TAG and PC by Perking Elmer. All chemicals were of analytical grade. All appropriate controls were performed and discounted.

After incubation, hemocytes and lipoproteins were isolated as mentioned before. With relation to lipoproteins in each ultracentrifugation aliquot; the presence of proteins was determined through absorbance at $280 \mathrm{~nm}$. Radioactivity of hemocytes and lipoproteins was measured by liquid scintillation in a Wallac 1214 Rack Beta equipment.

\section{Results}

Figure 1 shows a sample of adult female Grammostola rosea.

The absorbance at $280 \mathrm{~nm}$ measured in each aliquot after ultracentrifugation of the hemolymph showed a protein profile with two peaks (Figure 2). One of them was found in the high-density zone (1.13 - $1.15 \mathrm{~g} / \mathrm{ml}$ ) and was named Gr-HDL fraction, the other was found in the very-high-density zone $(1.24-1.27 \mathrm{~g} / \mathrm{ml})$ and named Gr-VHDL fraction.

Fractions corresponding to Gr-HDL and Gr-VHDL were analyzed separately. The amount of proteins in GrHDL and Gr-VHDL was 0.59 and $42.35 \mathrm{mg} / \mathrm{ml}$ of the hemolymph respectively. The quantity of lipids transported to each fraction was $0.35 \mathrm{mg} / \mathrm{ml}$ of hemolymph for Gr-HDL and $2.96 \mathrm{mg} / \mathrm{ml}$ for Gr-VHDL. With relation to the distribution of proteins and lipids in the hemolymph, Gr-VHDL fraction has the greatest \% of proteins and lipids (98.6\% and 89.3\%). The lipid \% of lipoproteic fraction was 37.2\% in Gr-HDL and 6.9\% in Gr-VHDL, respectively. The protein \% of lipoproteic fraction was $62.8 \%$ for Gr-HDL and 93.1\% for Gr-VHDL (Table 1).

Figure 3 shows the results obtained by electrophoretic analysis of Gr-HDL and Gr-VHDL under dissociating conditions. HDL displayed a predominant band of $93 \mathrm{kDa}$ and $249 \mathrm{kDa}$, and Gr-VHDL fraction a predominant band of $68 \mathrm{kDa}$ which would correspond to Hc and two others of 99 and $123 \mathrm{kDa}$.

With relation to the different lipids found in the lipoproteins, it was observed that Gr-HDL and Gr-VHDL fractions have similar \% of PC and PE (approximately 49\% and 35\% for each lipid). Significant differences be-

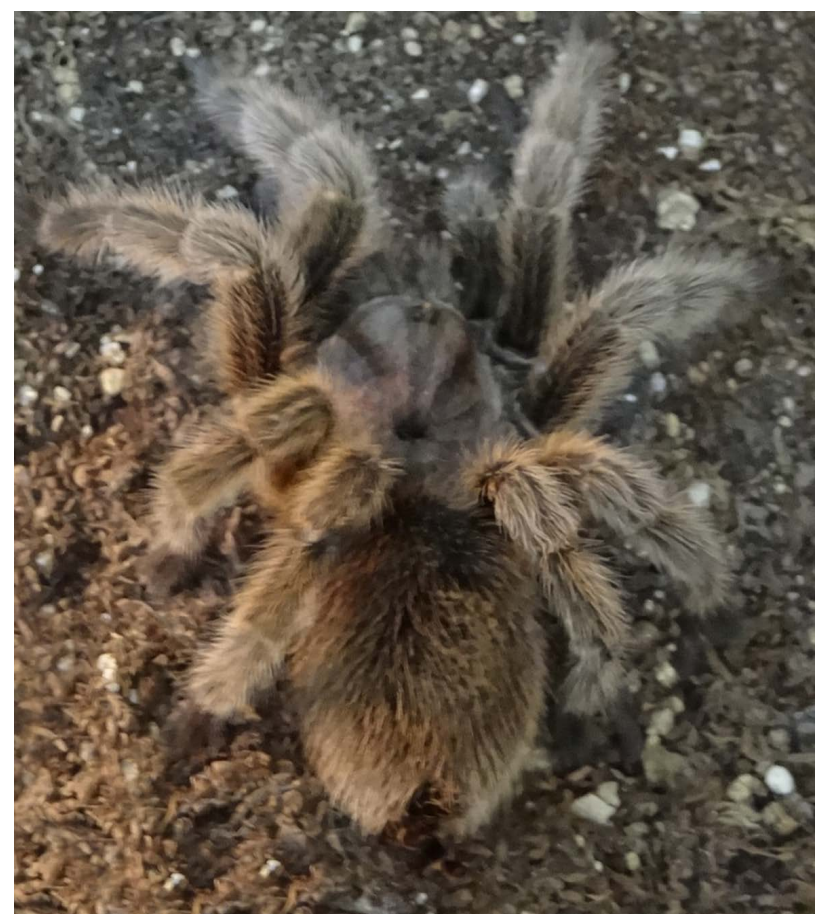

Figure 1. An adult female specimen of Grammostola rosea (Araneae, Theraphosidae). 


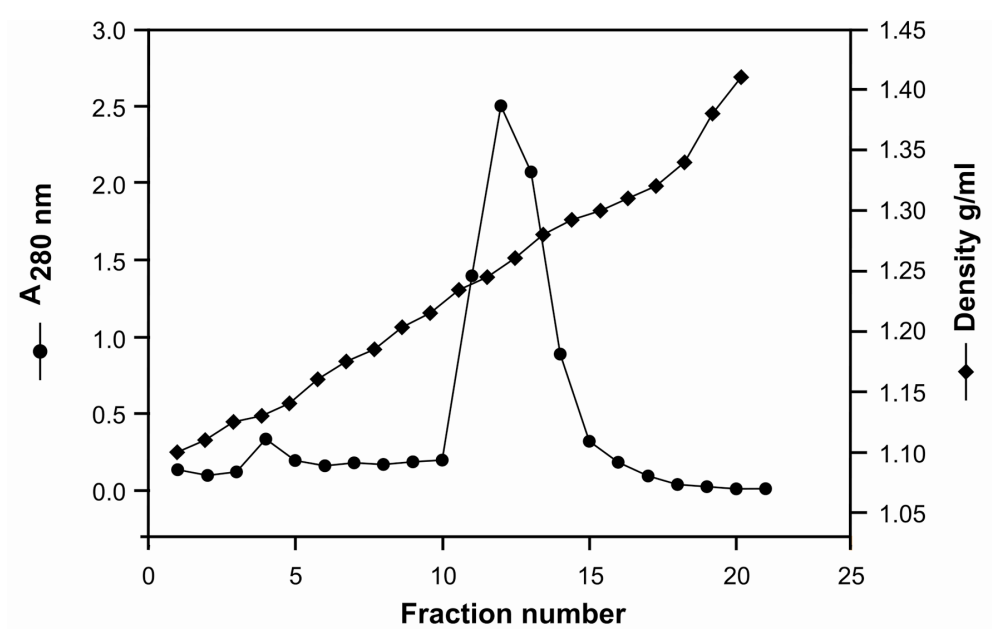

Figure 2. Protein distribution (absorbance at $280 \mathrm{~nm}$ ) of hemolymph from $G$. rosea obtained by gradient density ultracentrifugation in $\mathrm{NaBr} 1.35 \mathrm{~g} / \mathrm{ml}$.

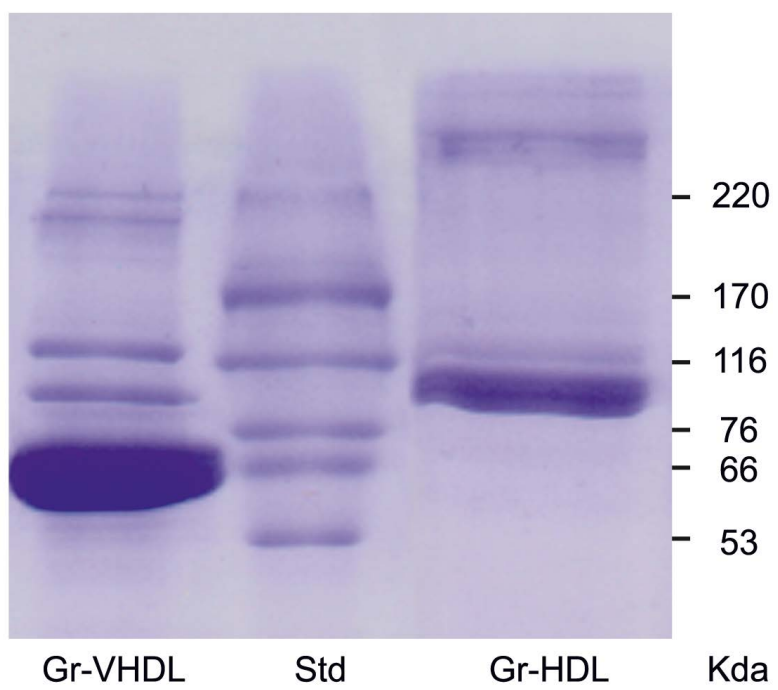

Figure 3. SDS-PAGE analysis of Gr-HDL and Gr-VHDL apoproteins from $G$. rosea hemolymph. The gels were done using polyacrylamide gradient of $4 \%-23 \% \mathrm{wt} / \mathrm{vol}$. The proteins were visualized by Coomasie Brillant Blue.

Table 1. Quantity and percentage of proteins and lipids in Gr-HDL and Gr-VHDL. Values are the means of three isolations of the hemolymph analyzed separately.

\begin{tabular}{ccc}
\hline & Gr-HDL & Gr-VHDL \\
\hline Hydrated density $(\mathrm{g} / \mathrm{ml})$ & $1.13-1.15$ & $1.24-1.27$ \\
Proteins $\mathrm{mg} / \mathrm{ml}$ hemolymph & $0.59 \pm 0.18$ & $42.35 \pm 4.6$ \\
Circulating proteins \% & 1.37 & 98.6 \\
Lipids $\mathrm{mg} / \mathrm{ml}$ hemolymph & $0.35 \pm 0.11$ & $2.96 \pm 0.32$ \\
Circulating lipids \% & 10.6 & 89.3 \\
Lipids \% of lipoproteic fractions & 37.2 & 6.9 \\
Proteins \% of lipoproteic fractions & 62.8 & 93.1 \\
Lipid/Protein ratio & 0.59 & 0.074 \\
\hline
\end{tabular}


tween both fractions were found in minority percentage, thus noticing in Gr-VHDL a lower \% of sphingomyelin [SM] and a major \% of COL, FFA, TAG and esterified sterol [SE] (Figure 4).

Figure 5 shows a comparative evaluation of the percentage of fatty acids present in Gr-HDL and Gr-VHDL fraction. As the \% is similar in both lipoproteins, the predominant fatty acids were in decreasing order: 18:1, 16:0, 18:2, 18:0, 14:0, 16:1 and 18:3, among others.

In vitro assays, FFA, TAG and PC were bound separately to the hemolymph, which was ultracentrifuged in density gradient, and the lipoproteic fractions Gr-HDL and Gr-VHDL were isolated. Radioactivity was measured in each aliquot and the lipoproteins were identified by their absorbance at $280 \mathrm{~nm}$ (Figure 6). In this figure it is observed that the radiolabelled TAG and FFA (in these two analyzed concentrations) bind mainly to Gr-VHDL fraction. On the contrary, PC was mainly found in Gr-HDL and in a lesser extent in Gr-VHDL fraction.

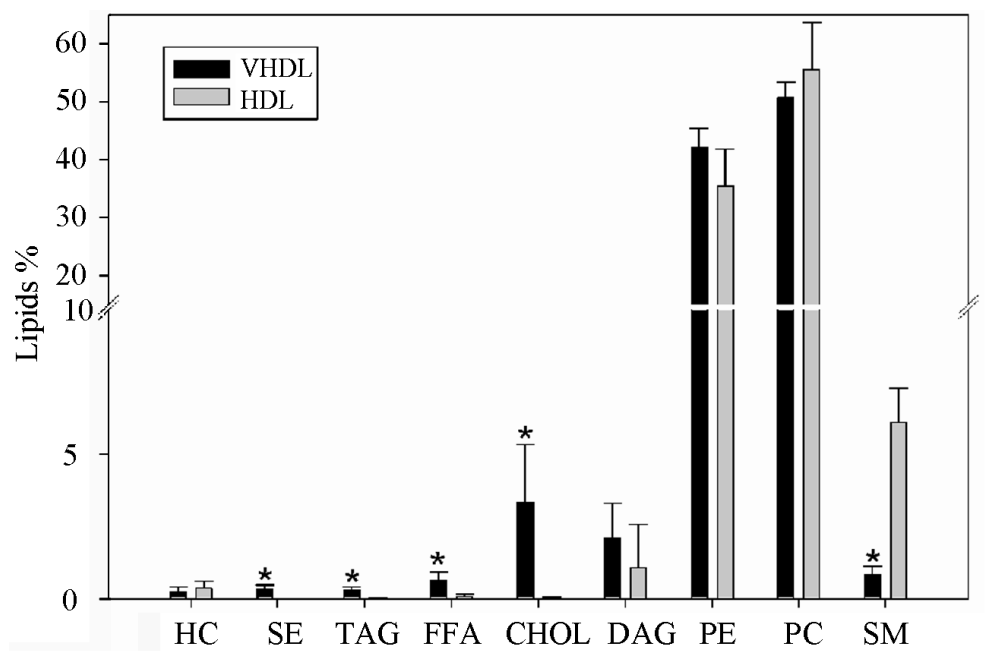

Figure 4. Lipid composition of Gr-HDL and Gr-VHDL form G. rosea. Data on lipid classes are expressed as weight percentage as determined and quantified by TLC-FID. Values represent the mean \pm SD of three independent analyses. Student's $t$ test was used to compare the significance of the differences between Gr-VHDL and Gr-HDL. ${ }^{*} \mathrm{P}<0.05$.

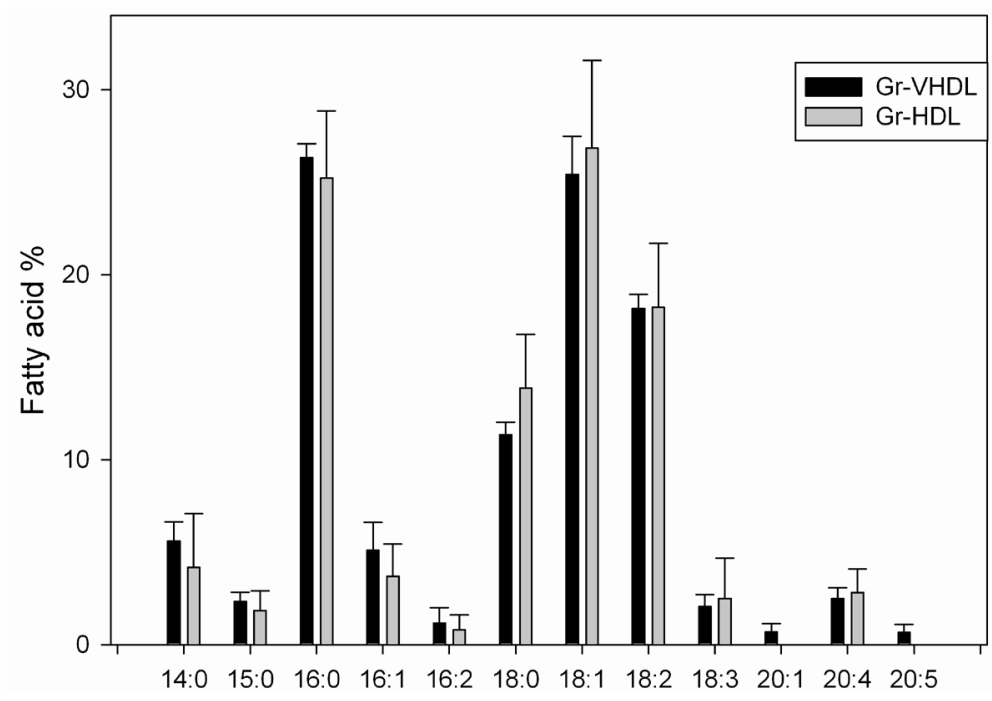

Figure 5. Fatty acid composition of Gr-HDL and Gr-VHDL isolated from hemolymph of $G$. rosea. Data are expressed as weight percentage and quantitified by GLC. Values are the mean \pm SD of three independent analyses. 


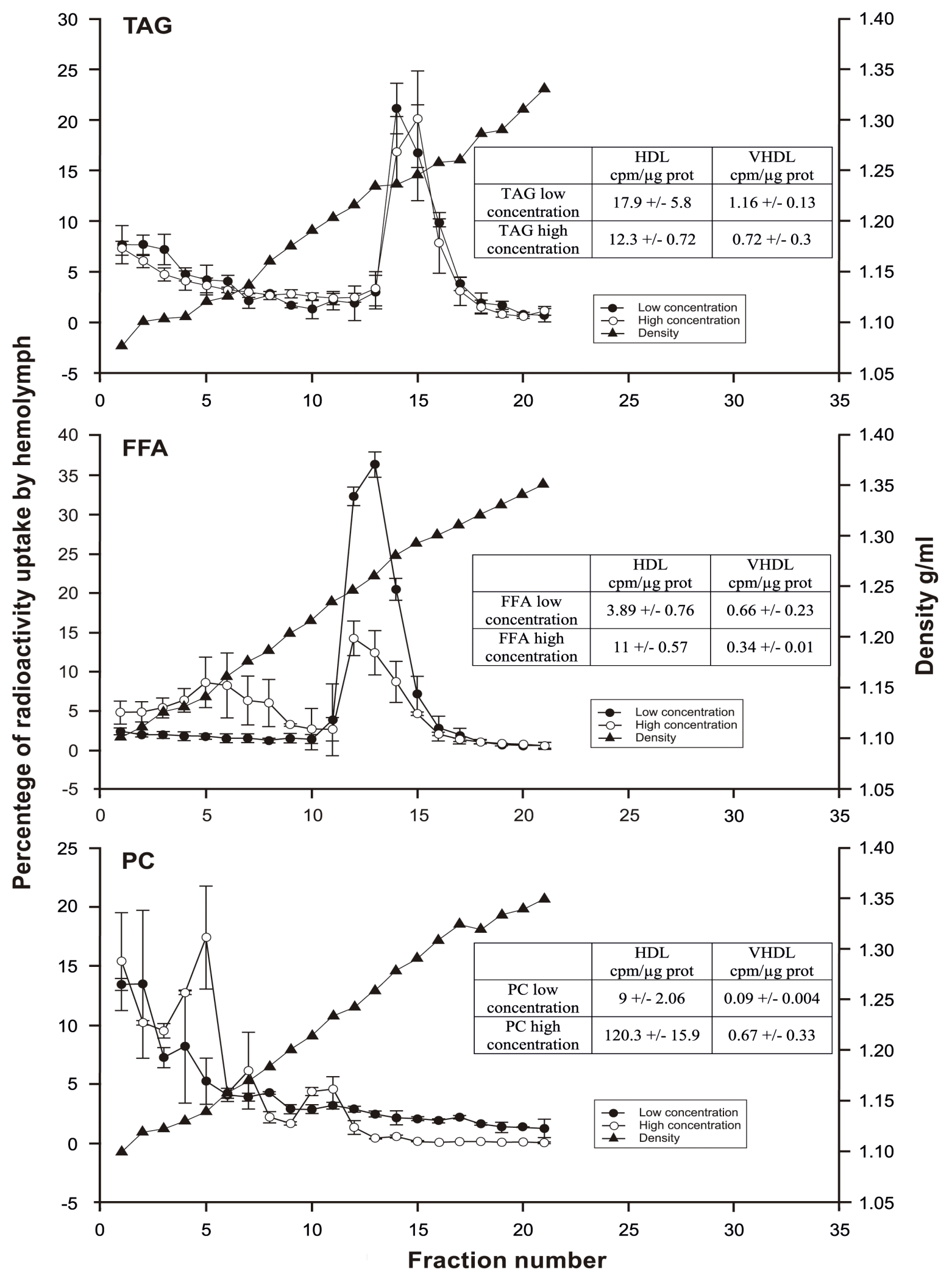

Figure 6. Radioactivity distribution in hemolymphatic fractions of $G$. rosea, after having incubated the hemolymph with different lipids $\left({ }^{14} \mathrm{C}\right.$-FFA, ${ }^{14} \mathrm{C}$-TAG and ${ }^{14} \mathrm{C}$-PC) and ultracentrifuged in a $\mathrm{NaBr}$ gradient. Results correspond to the mean \pm $\mathrm{SD}$ of three independent analyses. 
Insets show the specific activities of the two concentrations analyzed of the different lipids (TAG, FFA and PC), being majority in Gr-HDL with values ranging from 3.89 to $120 \mathrm{cpm} / \mu \mathrm{g}$ of protein and from 0.09 to 1.16 $\mathrm{cpm} / \mu \mathrm{g}$ of protein for Gr-VHDL.

Table 2 shows the \% of radiolabelled lipids, taken up by Gr-HDL, Gr-VHDL and hemocytes in the different assays of in vitro incubation. In Gr-HDL it was found about $22 \%$ of TAG, $8 \%$ and $36 \%$ of FFA, and $67 \%$ and $78 \%$ of PC. In the case of Gr-VHDL it was taken up approximately 75\% of TAG, $90 \%$ and $62 \%$ of FFA, and 30\% and $21 \%$ of PC. Hemocytes bind from $0.4 \%$ to $2.5 \%$ of radioactivity associated to the different lipids assayed.

\section{Discussion}

In the hemolymph of the tarantula $G$. rosea two lipoproteic fractions with densities corresponding to HDL and VHDL were identified and defined as Gr-HDL and Gr-VHDL.

Gr-HDL has a density (1.13 - $1.15 \mathrm{~g} / \mathrm{ml})$ similar to that reported for the HDL-1 of the spider L. mirabilis (1.13 $\mathrm{g} / \mathrm{ml}$ ) [12]. For the case of spiders P. pythagoricus and Aphonopelma hentzi in which two HDLs were reported, Gr-HDL coincides with P. pythagoricus HDL-1 (1.13 g/ml) [11] and with one of the Aphonopelma hentzi HDL $(1.14 \mathrm{~g} / \mathrm{ml})[16]$.

Molecular weights of apoliproteins (93 and $249 \mathrm{kDa}$ ) related to their electrophoretic mobility of Gr-HDL are similar to the apolipoproteins reported for the tarantula Aphonopelma hentzi and for the spider P. pythagoricus (80 and $250 \mathrm{kDa}$ ) [11] [15]. The term lipophorin proposed by Chino et al. [35] to designate insect lipoproteins with densities near $1.14 \mathrm{~g} / \mathrm{ml}$, capable of transporting majority DAG and which was previously applied to tarantula HDL [15] seems to be adequate for the present Gr-HDL because the presence of two apoliproteins of 250 280 and $75-78$ is characteristic of lipophorin [36].

The electrophoretic analysis of fraction VHDL under dissociating conditions shows one predominant protein band of $68 \mathrm{kDa}$ and two minority apoliproteins of 99 and $123 \mathrm{kDa}$. The band of $68 \mathrm{kDa}$ has a molecular weight similar to the Hc monomers found in other spiders [14] [37]-[39]. Whereas the other two minority bands have molecular weights similar to the apoliproteins described for VHDL of P. pythagoricus and Aphonopelma hentzi (105 and $121 \mathrm{kDa}$ ) [11] [15]. It is important to highlight that, as in the spider L. mirabilis [12], VHDL fraction showed three peaks with the same proteic compounds when subjected to chromatography of molecular exclusion, which was determined in the SDS-PAGE (data not shown).

The quantity of lipids associated with Gr-HDL is $37.2 \%$ which coincides with that reported for the tarantula Aphonopelma hentzi 40/44\% [15], but it is somewhat elevated in relation to that found in other non-Theraphosidae spiders as in L. mirabilis with 20\% [12] and in P. pythagoricus with 28\% [11]. With relation to the quantity of lipids found in Gr-VHDL fraction (6.9\%), it is similar to that described for P. pythagoricus (3\%) and rather higher for L. mirabilis (1\%) [12] [14].

At present, taking into account the quantity of works performed in this subject, (see review Cunningham et al., [13]) it is not surprising to find a lipoproteic fraction of high (HDL) or very high (VHDL) density with Hc, which was firstly described in the arachnids using P. pythagoricus (Sparassidae) by Cunningham and Pollero

Table 2. Percentage of the different lipids $\left({ }^{14} \mathrm{C}\right.$-FFA, ${ }^{14} \mathrm{C}$-TAG and ${ }^{14} \mathrm{C}$-PC) taken up by lipoproteic fractions after incubating in vitro for 1 hour, in $50 \mathrm{mM}$ potassium phosphate buffer $\mathrm{pH} 7.4$.

\begin{tabular}{|c|c|c|c|}
\hline & Gr-HDL & Gr-VHDL & Hemocytes \\
\hline $\begin{array}{c}\%{ }^{14} \mathrm{C}-\mathrm{TAG} \\
\text { (low concentration) }\end{array}$ & $22.40 \pm 2.53$ & $76.55 \pm 2.48$ & $1.04 \pm 0.05$ \\
\hline $\begin{array}{c}\%{ }^{14} \mathrm{C}-\mathrm{TAG} \\
\text { (high concentration) }\end{array}$ & $23.05 \pm 2.63$ & $75.12 \pm 3.18$ & $1.81 \pm 0.57$ \\
\hline $\begin{array}{c}\%{ }^{14} \mathrm{C}-\mathrm{FFA} \\
\text { (low concentration) }\end{array}$ & $8.11 \pm 1.78$ & $90.5 \pm 1.63$ & $1.37 \pm 0.27$ \\
\hline $\begin{array}{c}\%{ }^{14} \mathrm{C}-\mathrm{FFA} \\
\text { (high concentration) }\end{array}$ & $36.0 \pm 2.08$ & $62.15 \pm 2.25$ & $1.74 \pm 0.18$ \\
\hline $\begin{array}{c}\%{ }^{14} \mathrm{C}-\mathrm{PC} \\
\text { (low concentration) }\end{array}$ & $67.17 \pm 10.47$ & $30.28 \pm 9.16$ & $2.54 \pm 1.33$ \\
\hline $\begin{array}{c}\%{ }^{14} \mathrm{C}-\mathrm{PC} \\
\text { (high concentration) }\end{array}$ & $78.58 \pm 7.61$ & $21.01 \pm 7.66$ & $0.40 \pm 0.05$ \\
\hline
\end{tabular}


[14], and subsequently it was confirmed the presence of lipids in the lipoproteic fraction with Hc in L. mirabilis (Theridiidae) [12]. Using different radiolabelled lipids and in vivo and in vitro assays, the functionality of lipoproteic fractions with Hc in P. pythagoricus was studied throughout the last years by Cunningham et al. [18] [40] and Laino et al. [24] [25].

In the present work we are not able to find an explanation to the fact that there is a presumably different lipid transport system in a same arachnid family (Theraphosidae). Haunerland and Bowers [15] (using ultracentrifugation in a density gradient with $\mathrm{NaBr} 1.35 \mathrm{~g} / \mathrm{ml}$ ) describe that there are three proteic fractions of different density in the hemolymph of the tarantula Aphonopelma hentzi: HDL of $1.12 \mathrm{~g} / \mathrm{ml}$, VHDL of $1.28 \mathrm{~g} / \mathrm{ml}$ and Hc with other proteins $>1.28 \mathrm{~g} / \mathrm{ml}$. In this particular case with the tarantula $G$. rosea, employing a gradient of similar density ( $\mathrm{NaBr} 1.35 \mathrm{~g} / \mathrm{ml}$ ), the Gr-VHDL fraction with Hc showed a density of $1.24-1.27 \mathrm{~g} / \mathrm{ml}$, and proteins with higher density are not observed. This fact may be possible because Hc interacts with lipids, thus "floating" is achieved in that density. Therefore, Hc functions as lipid transport in arachnids does not seem to be general, since only in three out of the four studied species this function is observed. This discrepancy is not exclusive for arachnids as it was also observed in other invertebrates such as mollusks. In cephalopods Hc transports lipids [41], but in gastropods this phenomenon does not occur [42]. Numerous studies with new models are necessary in order to interpret these observations.

PC is generally in arthropod lipoproteins the majority structural lipid, which can be found in crustacean lipoproteins with $38 \%$ of total lipids in M. borellii and $46 \%$ in P. leniusculus [7] [43], and in arachnids lipoproteins with 31\% and 25\% in HDL-1 and HDL-2 fractions of L. mirabilis, 59\% in VHDL fraction of Aphonopelma hentzi and with 30\%, 22\% and 40\% in HDL-1, HDL-2 and VHDL of $P$. pythagoricus [11] [12] [14] [16]. In the present study the quantity of PC is rather greater, finding values of $55 \%$ and $49 \%$ in Gr-HDL fraction and Gr-VHDL respectively. PE\% in G. rosea (35\% - 42\%) is also greater to that described for arachnid lipoproteins (3.6\% - 15.2\%) [11] [12] [14] [16].

The present study is the first report that observes the presence of SM on arachnid lipoproteic fractions. It is likely that this lipid is found in other arachnid species where lipid characterization in lipoproteic fractions has been reported, but within the so-called other PL as the case of HDL-1 in P. pythagoricus (16\%) [11], HDL-2 (17.7\%) and VHDL (11.6\%) [14], or lipids unidentified in VHDL of Aphonopelma hentzi (10\%) [16]. Comparing the different lipids found in the two lipoproteic fractions, it is observed that Gr-HDL has greater percentage of SM than Gr-VHDL, and mainly greater \% of CHOL and lesser quantities of FFA and SE. With relation to CHOL it is important to highlight that Gr-VHDL possesses 100 more times CHOL in its structure than Gr-HDL, this difference coincides with that described by Cunningham et al. [11] [14] where it is observed that VHDL fraction (lipoproteic fraction with Hc) has CHOL in its structure, and being absent in HDL-1 (lipoproteic fraction without Hc). Moreover, VHDL of P. pythagoricus has the ability to bind (in vitro) CHOL 1070 more times than it normally does [18]. This pattern is also repeated when with-and-without-Hc HDL fractions are compared in L. mirabilis, thus finding CHOL 4.7 more times in the HDL with Hc. In 2000 Cunningham and collaborators suggest that lipoproteic fraction with Hc could be specialized in CHOL transport. Although available data are scarce since there are few studies on the subject, it is possible that Hc has different lipid binding or as mentioned by Cunningham et al. [12] Hc aggregates give rise to particles of different conformation, which are able to bind certain lipids.

The fatty acid compositions of fraction Gr-HDL and Gr-VHDL determined by GLC are shown comparatively in Figure 6. Here it is observed that both fractions have similar composition of fatty acids being majority fatty acids 18:1, 16:0, 18:2, 18:0 and 20:4. This coincides with that analyzed by Laino and collaborators in VHDL hexamer of P. pythagoricus (data not published), by Stratakis et al. [16] in VHDL of tarantula Aphonopelma hentzi 18:1 + 18:2 (52.3\%), 16:0 (24.9\%), and also in egg lipoproteins of the spiders P. pythagoricus and Schizocosa malitiosa with 18:1 (31\% and 24\%), 18:2 (26\% and 25\%), 16:0 (18\% and 20\%) [44] [45]. It is important to point out that also this pattern with 18:1 (30\%), 18:2 (23\%) and 16:0 (15\%) is also found in the biosynthetic organ of spider lipids (midgut diverticula of $P$. pythagoricus) [24]. Although it is described that the different dietary habits of arthropods can generate differences in the fatty acid composition of hemolymph [46], in the present work the comparison of the fatty acids of the lipoproteic fractions with the scarce existing data on hemolymph of Aphonopelma hentzi and $P$. pythagoricus leads us to think that either the dietary changes are very few or the present hypothesis does not seem to apply for arachnid lipoproteins.

Binding assays of different lipids to the hemolymphatic components demanded the adaptation of appropriate techniques for the three different lipid bindings. For the binding of TAG, the addition of an emulsifier such as 
sodium cholate and optimum incubation conditions were required; for PC, extruded liposomes were necessary; and ammonium salts were performed for FFA. As a consequence of these experiments it was observed that hemocytes participate in the uptake of different lipids (assays of in vitro incubation), the \% of taken-up lipids is similar to that previously observed in the hemocytes of the spider $P$. pythagoricus [25]. These results suggest that lipids of different polarities are taken up approximately in the same proportion by hemocytes $0.4 \%-2.5 \%$, opposed to that observed by Pollero et al. [47] where triolein ${ }^{14} \mathrm{C}$ and palmitic acid ${ }^{14} \mathrm{C}$ are taken up by mollusk hemocytes, $12 \%$ and $30 \%$ respectively.

On the other hand, it was observed that Gr-HDL takes up more ${ }^{14} \mathrm{C}-\mathrm{PC}$ than Gr-VHDL coinciding with in vitro experiments performed in P. pythagoricus with HDL lipoprotein and VHDL analyzed separately [25].

On the contrary, the greatest percentage of radiolabelled FFA and TAG is associated to Gr-VHDL lipoproteic fraction with Hc as apoliprotein. Cunningham et al. [18] with the study of lipid binding capacity of spider Hc explain the possible presence of hydrophobic zones in the protein that would generate zones of lipid binding. This may possibly occur in VHDL fraction of G. rosea. The greatest \% of TAG and FFA found in Gr-VHDL coincides with this observation. Moreover, despite the higher specific activities of FFA and TAG in Gr-HDL compared to Gr-VHDL fraction, the total amount of proteins, FFA, and TAG remains higher in Gr-VHDL, providing a greater FFA and TAG uptake.

In conclusion, the present study reports the lipid characterization of lipoproteic fractions found in the hemolymph of tarantula G. rosea. The role of each lipoproteic fraction in relation to lipid uptake is proven by in vitro assays. Similarities and differences according to its lipid and protein compositions are found when they are compared with the lipoproteins of the only three species of spiders studied.

\section{Acknowledgements}

This work was supported by grants from Consejo Nacional de Investigaciones Científicas y Técnicas (CONICET-PIP No. 075) and Agencia Nacional de Promoción Científica y Tecnológica (PICT No. 2010-1270), Argentina, M.C. and F.G. are members of CONICET, Argentina, A.L. is recipient of a fellowship from CONICET, Argentina, G.S. is PhD student of UNLP. The authors would like to thank Matias Pizon for the samples of G. rosea. Rosana del Cid for the revision of the English and Mario Ramos the figure design.

\section{References}

[1] Arrese, E.L., Gazard, J.L., Flowers, M.T., Soulages, J.L. and Wells, M.A. (2001) Diacylglycerol Transport in the Insect Fat Body: Evidence of Involvement of Lipid Droplets and the Cytosolic Fraction. Journal of Lipid Research, 42, 225234.

[2] Blacklock, B.J. and Ryan, R.O. (1994) Hemolymph Lipid Transport. Insect Biochemistry and Molecular Biology, 24, 855873. http://dx.doi.org/10.1016/0965-1748(94)90015-9

[3] Chino, H. (1985) Lipid Transport: Biochemistry of Hemolymph Lipophorin. In: Kerkut, G.A. and Gilbert, L.I., Eds., Comprehensive Insect Physiology, Biochemistry and Pharmacology, Pergamon Press, New York, Vol. 10, 115-135.

[4] Gonzalez, M.S., Rimoldi, O. and Brenner, R. (1995) Studies on Very-High-Density Lipoprotein of Triatoma infestans Hemolymph in Relation to Its Function as Free Fatty Acid Carrier. Comparative Biochemistry and Physiology B, 110, 767-775. http://dx.doi.org/10.1016/0305-0491(94)00202-6

[5] Soulages, J.L. and Wells, M.A. (1994) Effect of Diacylglycerol Content on Some Physicochemical Properties of the Insect Lipoprotein, Lipophorin. Correlation with the Binding of Apolipophorin-III. Biochemistry, 33, 2356-2362. http://dx.doi.org/10.1021/bi00175a002

[6] Chang, E.S. and O’Connor, J.M. (1983) Metabolism and Transport of Carbohydrates and Lipid. In: Mantel, L.H., Ed., The Biology of Crustacea, Academic Press, New York, 263-278.

[7] García, F., Cunningham, M., González Baró, M.R., Garda, H.A. and Pollero, R.J. (2002) Effect of Fenitrothion on the Physical Properties of Crustacean Lipoproteins. Lipids, 37, 673-679. http://dx.doi.org/10.1007/s11745-002-0948-5

[8] García, F., González Baró, M.R. and Pollero, R.J. (2002) Transfer of Lipids between Hemolymph and Hepatopancreas in the Shrimp Macrobrachium borellii. Lipids, 37, 581-585. http://dx.doi.org/10.1007/s11745-002-0936-9

[9] Lee, R.F. (1991) Lipoproteins from the Hemolymph and Ovaries of Marine Invertebrates. In: Gilles, R., Ed., Advances in Comparative and Environmental Physiology, Springer-Verlag, London, Vol. 7. 187-208. http://dx.doi.org/10.1007/978-3-642-75897-3_3

[10] Lee, R.F. and Puppione, D.L. (1978) Serum Lipoproteins in the Spiny Lobster, Panulirus interruptus. Comparative 
Biochemistry and Physiology B, 59, 239-243.

[11] Cunningham, M., Pollero, R.J. and Gonzalez, A. (1994) Lipid Circulation in Spiders. Transport of Phospholipids, Free Acids and Triacylglycerols as the Major Lipid Classes by a High-Density Lipoprotein Fraction Isolated from Plasma of Polybetes pythagoricus. Comparative Biochemistry and Physiology Part B: Comparative Biochemistry, 109, 333-338. http://dx.doi.org/10.1016/0305-0491(94)90017-5

[12] Cunningham, M., Gonzalez, A. and Pollero, R.J. (2000) Characterization of Lipoproteins Isolated from the Hemolymph of the Spider Latrodectus mirabilis. Journal of Arachnology, 28, 49-55. http://dx.doi.org/10.1636/0161-8202(2000)028[0049:COLIFT]2.0.CO;2

[13] Cunningham, M., García, F. and Pollero, R.J. (2007) Arachnid Lipoproteins: Comparative Aspects. Comparative Biochemistry and Physiology Part C, 146, 79-87.

[14] Cunningham, M. and Pollero, R.J. (1996) Characterization of Lipoprotein Fractions with High Content of Hemocyanin in the Hemolymphatic Plasma of Polybetes pythagoricus. Journal of Experimental Zoology, 274, 275-280. http://dx.doi.org/10.1002/(SICI)1097-010X(19960401)274:5<275::AID-JEZ2>3.0.CO;2-M

[15] Haunerland, N.H. and Bowers, W.S. (1987) Lipoproteins in the Hemolimph of the Tarantula, Eurypelma californicum. Comparative Biochemistry and Physiology Part B: Comparative Biochemistry, 86, 571-574. http://dx.doi.org/10.1016/0305-0491(87)90450-0

[16] Stratakis, E., Fragkiadakis, G. and Tentes, I. (1993) Purification and Properties of the Fatty Acid-Binding VHDL from the Hemolymph of the Spider Eurypelma californicum. Journal of Experimental Zoology, 267, 483-492. http://dx.doi.org/10.1002/jez.1402670503

[17] Bridges, C.R. (2001) Modulation of Haemocyanin Oxygen Affinity: Properties and Physiological Implications in a Changing World. Journal of Experimental Biology, 204, 1021-1032.

[18] Cunningham, M., Gomez, C. and Pollero, R.J. (1999) Lipid Binding Capacity of Spider Hemocyanin. Journal of Experimental Zoology, 284, 368-373. http://dx.doi.org/10.1002/(SICI)1097-010X(19990901)284:4<368::AID-JEZ2>3.0.CO;2-I

[19] Decker, H. and Rimke, T. (1998) Tarantula Hemocyanin Shows Phenoloxidase Activity. Journal of Biological Chemistry, 273, 25889-25892. http://dx.doi.org/10.1074/jbc.273.40.25889

[20] Decker, H. and Jaenicke, E. (2004) Recent Findings on Phenoloxidase Activity and Antimicrobial Activity of Hemocyanins. Developmental and Comparative Immunology, 28, 673-687. http://dx.doi.org/10.1016/j.dci.2003.11.007

[21] Jaenicke, E. and Decker, H. (2004) Functional Changes in the Family of Type 3 Copper Proteins in Evolution. European Journal of Chemical Biology, 5, 163-176.

[22] Terwilliger, N.B. (1998) Functional Adaptations of Oxygen-Transport Proteins. Journal of Experimental Biology, 201, 1085-1098.

[23] Zatta, P. (1981) Protein-Lipid Interactions in Carcinus maenas (Crustacea) Hemocyanin. Comparative Biochemistry and Physiology Part B: Comparative Biochemistry, 69, 731-735. http://dx.doi.org/10.1016/0305-0491(81)90377-1

[24] Laino, A., Cunningham, M., García, F. and Heras, H. (2009) First Insight into the Lipid Uptake, Storage and Mobilization in Arachnids: Role of Midgut Diverticula and Lipoproteins. Journal of Insect Physiology, 55, 1118-1124. http://dx.doi.org/10.1016/j.jinsphys.2009.08.005

[25] Laino, A., Cunningham, M., Heras, H. and García, F. (2011) In Vitro Lipid Transfer between Lipoproteins and MidgutDiverticula in the Spider Polybetes pythagoricus. Comparative Biochemistry and Physiology Part B: Biochemistry and Molecular Biology, 160, 181-186. http://dx.doi.org/10.1016/j.cbpb.2011.08.003

[26] Baumann, T., Kuhn-Nentwig, L., Largiadèr, C.R. and Nentwig, W. (2010) Expression of Defensins in Non-Infected Araneomorph Spiders. Cellular and Molecular Life Sciences, 67, 2643-2651. http://dx.doi.org/10.1007/s00018-010-0354-2

[27] Garcia, F., Cunningham, M., Soulages, J.L., Garda, H.A. and Pollero, R.J. (2006) Structural Characterization of the Lipovitellin from the Shrimp Macrobrachium borellii. Comparative Biochemistry and Physiology Part B: Biochemistry and Molecular Biology, 145, 365-370. http://dx.doi.org/10.1016/j.cbpb.2006.08.014

[28] Lowry, O.H., Rosenbrough, N.J., Farr, A.L. and Randall, R. (1951) Protein Measurement with the Folin Phenol Reagent. Journal of Biological Chemistry, 193, 265-275.

[29] Laemmli, U.K. (1970) Cleavage of Structural Proteins during the Assembly of the Head of Bacteriophage T4. Nature, 227, 680-685. http://dx.doi.org/10.1038/227680a0

[30] Garín, C.F., Heras, H. and Pollero, R.J. (1996) Lipoproteins of the Egg Perivitellin Fluid of Pomacea canaliculata Snails (Mollusca: Gastropoda). Journal of Experimental Zoology, 276, 307-314. http://dx.doi.org/10.1002/(SICI)1097-010X(19961201)276:5<307::AID-JEZ1>3.0.CO;2-S

[31] Folch, J., Lees, M. and Sloane-Stanley, G.H. (1957) A Simple Method for the Isolation and Purification of Total Lipids 
from Animal Tissues. Journal of Biological Chemistry, 226, 497-509.

[32] Ackman, R.G., McLeod, C. and Banerjee, A.K. (1990) An Overview of Analyses by Chromarod-Iatroscan TLC-FID. Journal of Planar Chromatography, 3, 450-490.

[33] Morrison, W.R. and Smith, L.M. (1992) Preparation of Fatty Acid Methyl Esters and Dimethylacetals from Lipid with Boron Fluoride-Methanol. Journal of Lipid Research, 5, 600-608.

[34] Garcia, F., González Baró, M.R. and Pollero, R.J. (2005) Effect of Fenitrothion on the Acylglyceride Exchang in Crustacean Lipoproteins. Pesticide Biochemistry and Physiology, 82, 177-184. http://dx.doi.org/10.1016/j.pestbp.2004.11.005

[35] Chino, H., Downer, R.G., Wyatt, G. and Gilbert, L.I. (1981) Lipophorins, a Major Class of Lipoproteins of Insect Hemolimph. Insect Biochemistry, 11, 491. http://dx.doi.org/10.1016/0020-1790(81)90085-8

[36] Chapman, M.J. (1983) A Broad Perspective on Invertebrate and Lower Vertebrate Apolipoproteins: Crustaceans, Insects. Fish, Amphibians, and Reptiles. In: Lewis, L.A. and Naito, H.K., Eds., Handbook of Electrophoresis, Vol. 4, CRC Press, Boca Raton, 285-310.

[37] Lamy, J., Lamy, J., Weill, J., Markl, J., Schneider, H.J. and Linton, S.M. (1979) Hemocyanins in Spiders. VII. Inmunologycal Comparison of the Subunits of Eurypelma californicum. Hoppe-Seyler's Zeitschrift für Physiologische Chemie, 360, 889-895. http://dx.doi.org/10.1515/bchm2.1979.360.2.889

[38] Markl, J. (1986) Evolution and Function of Structurally Diverse Subunits in the Respiratory Protein Hemocyanin from Arthropods. Biological Bulletin, 171, 90-115.

[39] Schneider, H.J., Markl, J., Schartau, W. and Linzen, B. (1977) Hemocyanins in Spiders. IV. Subunits Heterogeneity of Eurypelma californicum (Dugesiella) Hemocyanin, and Separation of Polypeptide Chains. Hoppe-Seyler's Zeitschrift für Physiologische Chemie, 358, 1133-1141. http://dx.doi.org/10.1515/bchm2.1977.358.2.1133

[40] Cunningham, M., Garcia, F., Garda, H. and Pollero, R. (2006) Hemocyanin Lipid Uptake in Polybetes pythagoricus Is Altered by Fenitrothion. Pesticide Biochemistry and Physiology, 86, 57-62. http://dx.doi.org/10.1016/j.pestbp.2005.11.006

[41] Heras, H. and Pollero, R.J. (1990) Occurrence of Plasma Lipoproteins in Octopods. Partial Characterization and Interorgan Transport of Lipids. Journal of Experimental Marine Biology and Ecology, 140, 29-38. http://dx.doi.org/10.1016/0022-0981(90)90078-Q

[42] Pollero, R.J., González Baró, M.R. and Garín, C.F. (1992) Lipid Transport in Snails. Partial Characterization of a High-Density Lipoprotein Isolated from Ampullaria canaliculata Plasma. Comparative Biochemistry and Physiology Part B: Biochemistry and Molecular Biology, 102, 717-720.

[43] Hall, M., van Heusden, M.C. and Söderhäll, K. (1995) Identification of the Major Lipoproteins in Crayfish Hemolymph as Proteins Involved in Immune Recognition and Clotting. Biochemical and Biophysical Research Communications, 216, 939-946. http://dx.doi.org/10.1006/bbrc.1995.2711

[44] Laino, A., Cunningham, M., Heras, H. and Garcia, F. (2011) Isolation and Characterization of Two Vitellins from Eggs of the Spider Polybetes pythagoricus (Araneae: Sparassidae). Comparative Biochemistry and Physiology Part B: Biochemistry and Molecular Biology, 158, 142-148. http://dx.doi.org/10.1016/j.cbpb.2010.11.001

[45] Laino, A., Cunningham, M., Costa, F.G. and Garcia, F. (2013) Energy Sources from the Eggs of the Wolf Spider Schizocosa malitiosa: Isolation and Characterization of Lipovitellins. Comparative Biochemistry and Physiology Part B: Biochemistry and Molecular Biology, 165, 172-180. http://dx.doi.org/10.1016/j.cbpb.2013.04.004

[46] Schartau, W. and Leidescher, T. (1983) Composition of the Hemolymph of the Tarantula Eurypelma californicum. Journal of Comparative Physiology, 152, 73-77. http://dx.doi.org/10.1007/BF00689730

[47] Pollero, R.J., Huca, G. and Brenner, R.R. (1985) Role of Hemocytes and Plasma on Lipid Transport in the Freshwater Mollusc Diplodon delodontus. Comparative Biochemistry and Physiology Part A: Physiology, 82, 339-343. http://dx.doi.org/10.1016/0300-9629(85)90865-5 
Scientific Research Publishing (SCIRP) is one of the largest Open Access journal publishers. It is currently publishing more than 200 open access, online, peer-reviewed journals covering a wide range of academic disciplines. SCIRP serves the worldwide academic communities and contributes to the progress and application of science with its publication.

Other selected journals from SCIRP are listed as below. Submit your manuscript to us via either submit@scirp.org or Online Submission Portal.
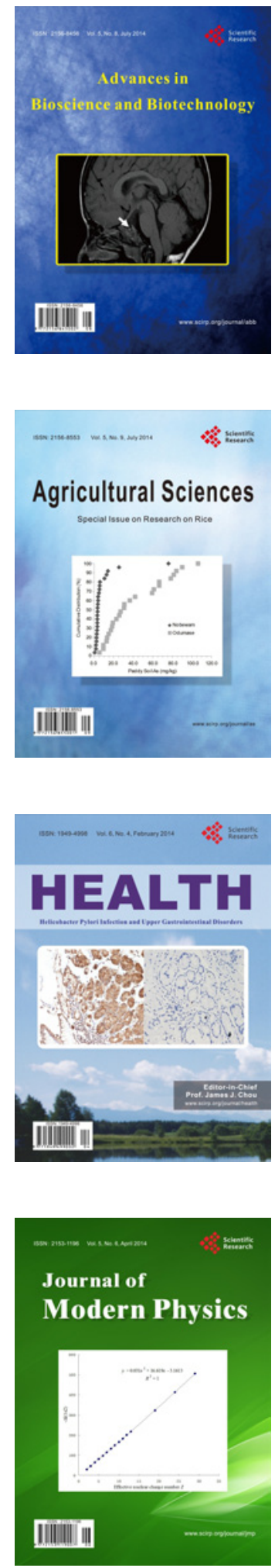
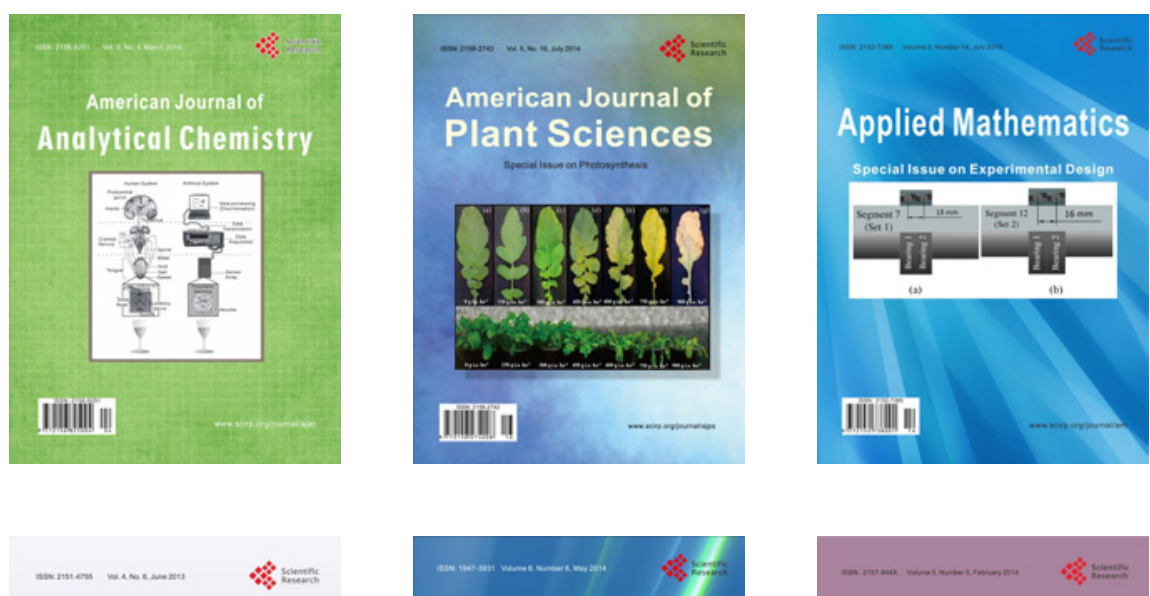

Creative Education
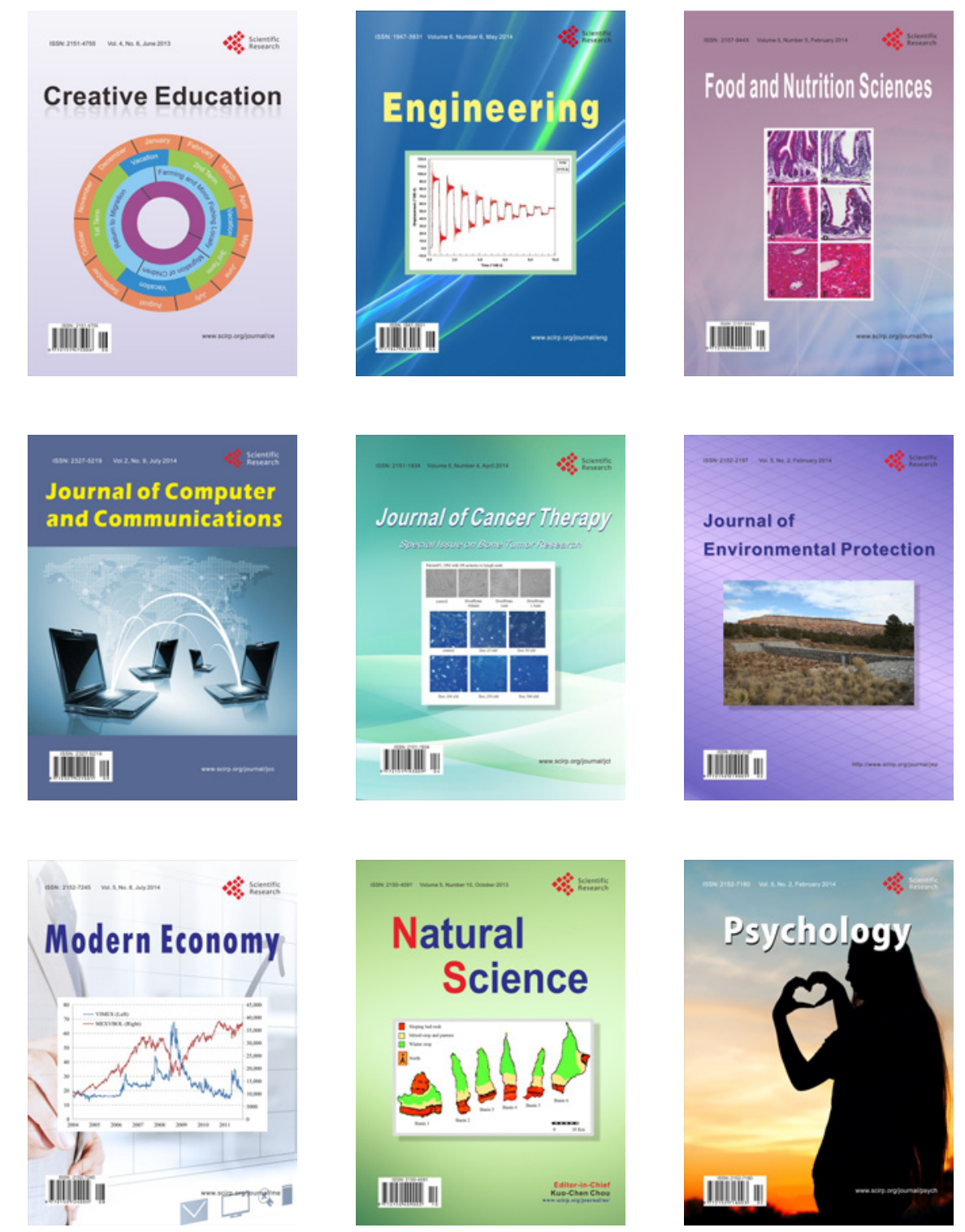